https://doi.org/10.15407/ujpe65.9.778

L.A. BUlavin, ${ }^{1}$ A.E. MiKHAILOV ${ }^{2}$ P.K. KUZMICHEV,${ }^{2}$ V.V. CHUPIN,${ }^{2}$

V.I. BORSHCHEVSKIY ${ }^{2}$ I.V. CHIZHOV ${ }^{3}$ D.V. SOLOVIOV $^{2,4,5}$

1 Taras Shevchenko National University of Kyiv

(60, Volodymyrs'ka Str., Kyiv 01601, Ukraine)

2 Moscow Institute of Physics and Technology

(9, Institutskii Lane, Dolgoprudny 141700, Moscow Region, Russian Federation)

${ }^{3}$ Medizinische Hochschule Hannover

(Carl-Neuberg-Str. 1, 30625 Hannover, Deutschland)

${ }^{4}$ Institute for Safety Problems of Nuclear Power Plants, Nat. Acad. of Sci. of Ukraine

(36a, Kirova Str., Chornobyl 07270, Kyiv Region, Ukraine)

${ }^{5}$ Joint Institute for Nuclear Research

(6, Joliot-Curie Str., Dubna 141980, Russian Federation; e-mail: DmitrySoloviov@jinr.ru)

\title{
INFLUENCE \\ OF CHOLESTEROL CONCENTRATION ON BACTERIORHODOPSIN PHOTOCYCLE
}

\begin{abstract}
The photocycle of the membrane protein bacteriorhodopsin in Dipalmitoylphosphatidyl-

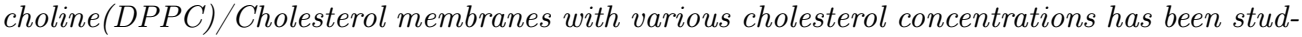
ied using the time-resolved spectroscopy method. The temperature dependences of the rate constants of bacteriorhodopsin transitions between transient states are shown to satisfy the Eyring equation. It is proved that the growth of the cholesterol concentration in the DPPC membrane accelerates the bacteriorhodopsin photocycle.
\end{abstract}

Ke ywords: laser photolysis, lipid membranes, photocycle, bacteriorhodopsin, cholesterol.

\section{Introduction}

Lipid membranes are an important component of living organisms, because they regulate plenty of the processes that are required to maintain the viability of every cell and cell organelles. That is why a considerable number of works on biophysics is devoted to the study of phase transitions in lipid membranes and their dependence on the temperature and pressure [1-4], the structural characteristics of various lipid phases [5,6], the influence of various impurities on the properties of membranes [7-11], as well as to the measurement of the dynamic characteristics of singleand multicomponent membranes $[12,13]$.

One of the most important functions of the lipid membrane is to provide the functioning of membrane proteins. It is the lipid membrane that is assumed to control the activity of proteins [14], in particular, by changing its phase state and composition. The study of lipid-protein interactions is a rather challenging

(C) L.A. BULAVIN, A.E. MIKHAILOV, P.K. KUZMICHEV, V.V. CHUPIN, V.I. BORSHCHEVSKIY, I.V. CHIZHOV, D.V. SOLOVIOV, 2020 task, because it helps to better understand the functioning mechanisms of membrane proteins.

One of the most wide-spread components of the eukaryotic cell membranes is cholesterol, the fraction of which reaches 20-30 mol\% [15]. An excess of cholesterol in the body leads to the development of gallstone disease, upsets metabolism, and promotes the formation of various depositions in the organism. Recent studies testify that it is excess cholesterol that is actively involved in the formation of amyloid plaques giving rise to Alzheimer's disease [15, 16]. From the viewpoint of the lipid membrane structure, cholesterol plays a role of a peculiar modifier of the lipid phase [15, 17-19]. An increase of its amount in the membrane leads to a denser packing of molecules in the lipid bilayer [20].

With regard for the role of cholesterol in the life of living organisms, we decided to consider its influence on the functioning of membrane proteins. The membrane protein bacteriorhodopsin (BR), one of the most studied photoactive proton pumps [21], was chosen as the object of research. Proton pumping occurs as a result of the series of BR conformational tran-

ISSN 2071-0194. Ukr. J. Phys. 2020. Vol. 65, No. 9 
sitions. In the course of this process, five intermediate forms of BR are distinguished. Each of them is characterized by the light absorption with a characteristic maximum at a certain wavelength. The photocycle measurement (times of the protein staying in each transient form) is a direct method of determining the influence of external conditions on the protein functioning [22-24].

This work is devoted to the application of the laser flash photolysis method to study the photocycle of the BR embedded into Dipalmitoylphosphatidylcholine (DPPC) vesicles with various cholesterol concentrations in them.

\section{Materials and Methods}

\subsection{Sample preparation}

To study the dependence of the BR kinetics on the lipid composition in the surrounding membrane, four samples of DPPC-based vesicles with different cholesterol contents were prepared: $0,6.5,18$, and $35 \mathrm{~mol} \%$. DPPC and cholesterol were obtained from the Avanti Polar Lipids Co. and used without additional purification. The total lipid mass (DPPC and cholesterol) was $20 \mathrm{mg}$ in each sample. The resulting lipid mixtures were dissolved in $1 \mathrm{ml}$ of trifluoroethanol with a small chloroform admixture (less than 1\%) in order to obtain homogeneous lipid mixtures. The solutions were thoroughly stirred and kept at room temperature for several hours. Afterward, the organic solvents were evaporated until lipid films were formed in each of the four reservoirs. Then, the samples were held for two days in a vacuum chamber to ultimately remove the organic solvents from them.

For the coarse purification of BR, a phosphate buffer solution with the acidity of $\mathrm{pH}=6.94$ and containing the sodium salt with a concentration of $20 \mathrm{mmol} / \mathrm{l}$ - those parameters are natural for BR was prepared. For the purification, the protein solution (with a protein concentration of about $8 \mathrm{mg} / \mathrm{ml}$ ) was washed three times with the phosphate buffer and subjected to the 90-min centrifugation at an acceleration of $20000 \mathrm{~g}$. The lipid residues of the native membrane were removed from the protein solution by adding the detergent octyl-beta-glucoside (OBG) to the latter and repeating the centrifugation procedure.

Hence, after the purification, we obtained a protein solution in which BR molecules were solubilized by the detergent OBG. This solution was added to a vessel containing the previously dried lipid films. In each of the four samples, the molar ratio between the total amounts of lipids and protein was $300: 1$. In order to remove the detergent from each sample, the non-polar adsorbent Bio-Beads SM-2 Resin (Bio-Rad, USA) was used. It is widely applied for the selective removal of organic substances from aqueous systems. The adsorbent mass was 20 times the detergent mass in each solution.

At the final stage, four samples - aqueous systems containing lipid vesicles with embedded BR protein molecules - with different cholesterol concentrations were obtained. To homogenize the samples, they were extruded through a filter with a pore diameter of $100 \mathrm{~nm}$. It was done to obtain vesicles with small sizes, which are transparent in the visible light spectral interval.

\subsection{Laser flash photolysis}

The laser flash photolysis method consists in measuring the time dependence of the light transmittance through a sample at a certain wavelength. The research was performed on a specially designed installation, the schematic diagram of which is shown in Fig. 1.

A quartz cuvette with the sample was mounted on a special holder (Quantum, Norway). Inside the latter, a given temperature was maintained with an accuracy of $0.05{ }^{\circ} \mathrm{C}$. To excite the BR photocycle, a Nd:YAG laser Brilliant B (Quantel, France) equipped with an optical parametric oscillator MagicPrism (Opotec, Carlsbad, USA) was used. It generated a laser beam $6 \mathrm{~mm}$ in diameter and a pulse duration of $4 \mathrm{~ns}$. The light wavelength can be varied from 400 to $700 \mathrm{~nm}$. As a source of probing radiation, a 75-W Hamamatsu xenon lamp (Japan) in combination with an MSH-150 monochromator (LOT, Germany) was used. The detector system included a photoelectronic multiplier R12829 and two DSOX4022A oscilloscopes (Keysight) with a bandwidth of $200 \mathrm{MHz}$.

\section{Results and Their Discussion}

To study the dependence of the characteristic features in the bacteriorhodopsin kinetics on the composition content in lipid membranes, four liposome samples with different cholesterol concentrations were prepared. Each sample was measured using the laser 


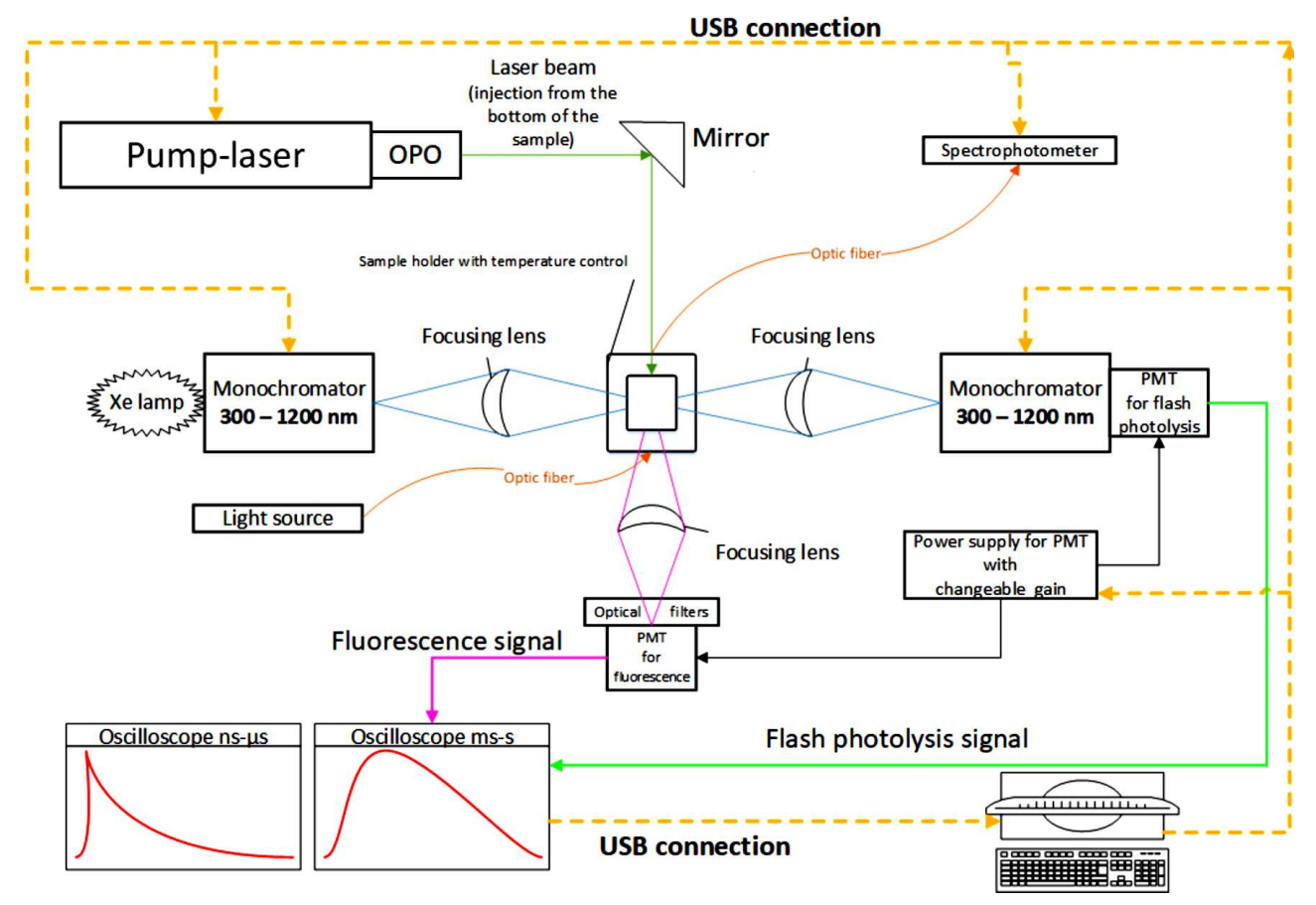

Fig. 1. Schematic diagram of the laser photolysis installation

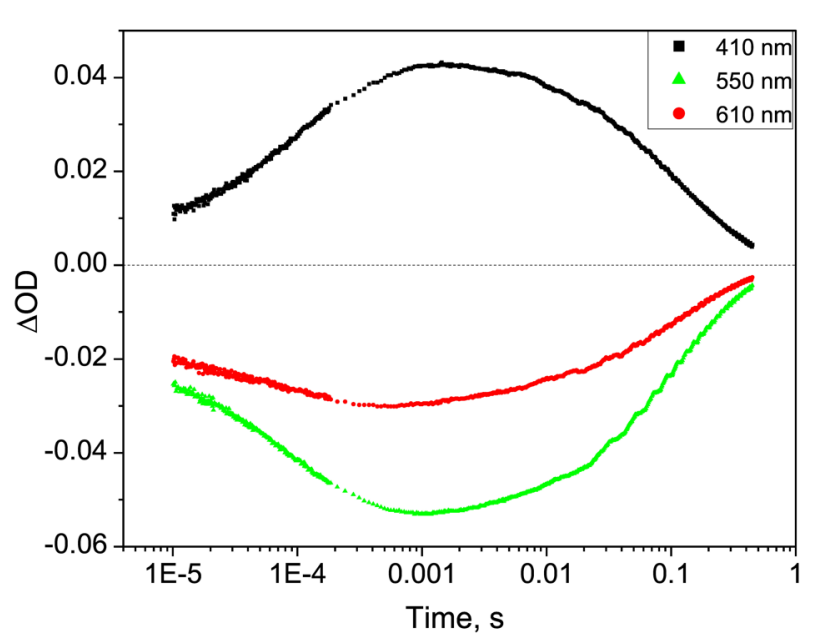

Fig. 2. Time dependences of the optical density changes of the bacteriorhodopsin sample with the $35 \%$ cholesterol concentration in the membrane at a temperature of $10{ }^{\circ} \mathrm{C}$ for various probing radiation wavelengths: 410 (squares), 550 (triangles), and $610 \mathrm{~nm}$ (circles)

flash photolysis method within the wavelength interval of probing radiation from 330 to $730 \mathrm{~nm}$ with an increment of $10 \mathrm{~nm}$. The measurements were performed at temperatures of $10,20,30$, and $40{ }^{\circ} \mathrm{C}$. In order to reduce the statistical error, the time dependence of the light transmittance at every examined wavelength was independently measured 25 times for each sample. As a result, a set of 41 experimental dependences for the change of the optical density of the protein solution in time was obtained for each sample.

Figure 2 demonstrates the time dependences of the optical density $\triangle O D_{\lambda}$ obtained for the bacteriorhodopsin sample with a $35 \%$ cholesterol concentration in the membrane. The dependences were measured at a temperature of $10{ }^{\circ} \mathrm{C}$ and various probing radiation wavelengths: 410 (squares), 550 (triangles), and $610 \mathrm{~nm}$ (circles). The magnitudes of the rate constants $k_{i}$ for the transitions between the transient $\mathrm{BR}$ states, the set of $\triangle O D_{\lambda}$ values at each temperature was approximated by the sum of five exponential functions (according to the number of transient BR states),

$\Delta O D_{\lambda}(t)=\sum_{i=1}^{5} A_{i \lambda} e^{-k_{i} t}$.

The experimental data were analyzed with the help of the software MEXFIT [25]. The results obtained were tested by comparing the model curves with the 
corresponding experimental results. This procedure is described in work [21] in more details.

As a result of fitting the experimental data that were measured for each sample at a given temperature, a set of rate constants describing the BR photocycle was obtained. An analysis of the rate constant dependences on the inverse temperature $1 / T$ testifies that the rate constants change according to Eyring's law

$\ln \left(k_{i}\right)=\ln \frac{R}{N_{A} h}+\frac{\Delta S_{i}}{R}-\ln \frac{1}{T}-\frac{1}{T} \frac{\Delta H_{i}}{R}$,

where $R$ is the universal gas constant, $h$ Planck's constant, $N_{A}$ the Avogadro number, and $\Delta S_{i}$ and $\Delta H_{i}$ are the activation entropy and enthalpy, respectively. In Fig. 3, an example of this dependence is exhibited for the rate constants of the bacteriodopsin sample with the $35 \%$ concentration of cholesterol in the membrane. The right-hand axis of the plot gives the transition half-time $\tau_{i}$, which is related to the transition rate constant $\tau_{i}$ by the formula $\tau_{i}=(\ln 2) / k_{i}$.

When comparing the experimental time dependences of the changes in the optical densities obtained for the samples with various cholesterol contents, one can see that the duration of the BR photocycle decreases, as the cholesterol content in the membrane increases. In Table, the half-times of BR transitions between the transient states at a temperature of $20^{\circ} \mathrm{C}$ are quoted for various concentrations of cholesterol in the membrane. According to the literature data [21], the duration of the photocycle of BR in its natural membrane does not exceed $25 \mathrm{~ms}$ at a temperature of $20{ }^{\circ} \mathrm{C}$. At the same time, the duration of the BR photocycle in a DPPC membrane in the absence of cholesterol increases to $120 \mathrm{~ms}$ (see Table, column $\tau_{5}$ ). The growth of the cholesterol concentration in the membrane accelerates the BR photocycle, so that if the cholesterol content equals $35 \%$, the BR transition into the latest transient state occurs during $70 \mathrm{~ms}$.

It should be noted that cholesterol does not enter the composition of bacterial membranes, i.e. it is not a natural component of the BR protein. Bearing this fact in mind, we may assert with a high degree of confidence that the acceleration of the BR photocycle is not associated with the direct interaction between $\mathrm{BR}$ and cholesterol. Therefore, the main reason for the photocycle kinetics to change is a modification

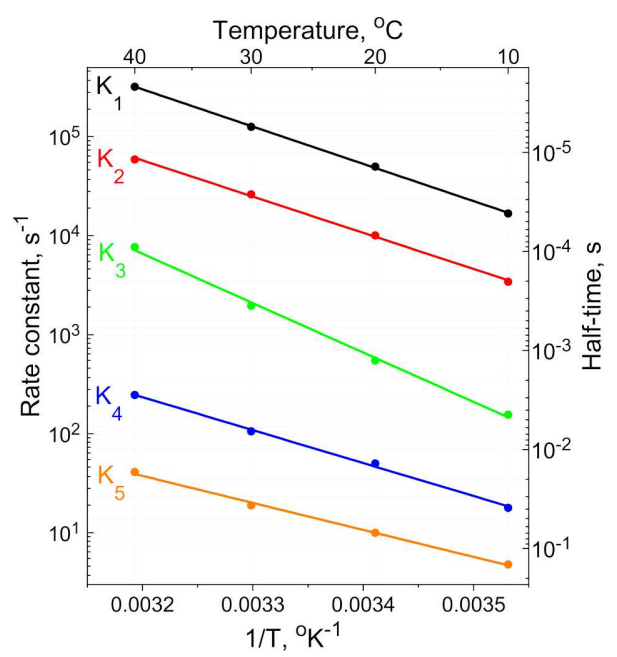

Fig. 3. Dependences of the rate constants for the transitions between the transient states of the bacteriodopsin sample with a cholesterol concentration of $35 \%$ on the inverse temperature

in the structure of the membrane itself invoked as a result of the cholesterol adding.

The authors of work [26] studied the influence of bacteriodopsin on the temperature of the main phase transition in phospholipid membranes making use of the differential scanning calorimetry method. It was shown that if bacteriodopsin is added to dimeristoylphosphatidylcholine (DMPC) membranes, the temperature of the main phase transition in the membrane increases by $5{ }^{\circ} \mathrm{C}$. The cited authors explain this phenomenon from the viewpoint of the ratio between the size of the hydrophobic part of bacteriodopsin and the lipid membrane thickness. The hydrophobic part of bacteriodopsin has a larger thickness, which results in an artificial growth of the membrane thickness around the protein. But this growth

Comparison of half-times

of bacteriodopsin transitions into transient states at a temperature of $20{ }^{\circ} \mathrm{C}$ for various concentrations of cholesterol in the membrane

\begin{tabular}{|c|c|r|r|r|r|}
\hline $\begin{array}{c}\text { Cholesterol } \\
\text { concentration, } \\
\text { mol\% }\end{array}$ & $\begin{array}{c}\tau_{1}, \\
\mu \mathrm{s}\end{array}$ & $\begin{array}{c}\tau_{2}, \\
\mu \mathrm{s}\end{array}$ & $\begin{array}{c}\tau_{3}, \\
\mu \mathrm{s}\end{array}$ & $\begin{array}{c}\tau_{4}, \\
\mu \mathrm{s}\end{array}$ & $\begin{array}{c}\tau_{5}, \\
\mu \mathrm{s}\end{array}$ \\
\hline 0 & 1.5 & 60 & 1300 & 27000 & 120000 \\
6.5 & 1.5 & 70 & 840 & 23000 & 100000 \\
18 & 1.6 & 70 & 8500 & 16000 & 82000 \\
35 & 1.4 & 7 & 1300 & 14000 & 70000 \\
\hline
\end{tabular}



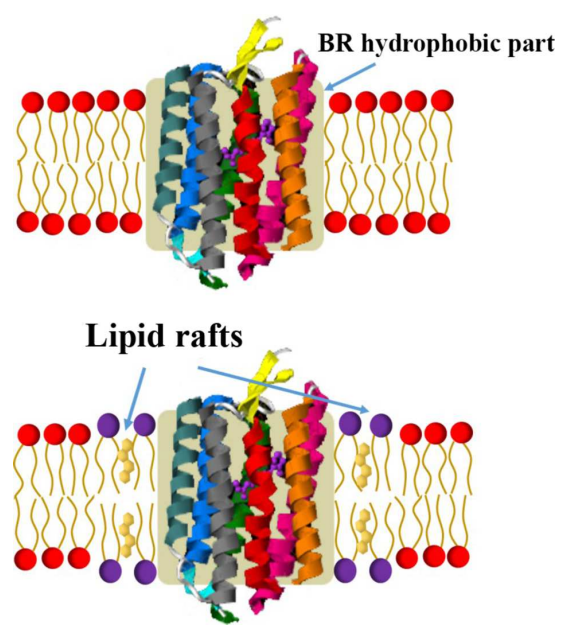

Fig. 4. Bacteriorhodopsin in the lipid membrane of DPPC in the absence of cholesterol (top panel) and the growth of the membrane thickness around the protein due to the formation of domains (bottom panel)

is possible only provided that the lipid tails are elongated as much as possible. Therefore, for the tails of lipid molecules located around the protein to melt, more energy is required than for molecules not adjacent to the protein. The cited authors marked that the growth of the main phase transition temperature in the presence of bacteriodopsin was also observed for DPPC-based membranes. However, the temperature difference was smaller, because the DPPC-based membranes are thicker than the DMPC ones.

Since the described lipid-protein interaction is rather strong, it evidently affects not only the lipid but also the protein. Therefore, the deceleration of the BR photocycle in the absence of cholesterol can be explained by the thickness difference between the DPPC lipid bilayer and the hydrophobic part of the protein (Fig. 4, top panel).

On the other hand, the addition of even a small amount of cholesterol to the membrane brings about the formation of domains in it [13], whose thickness is larger than the thickness of single component membrane [20]. The arrangement of the domains around the BR molecules reduces the local difference between the thicknesses of the hydrophobic part of protein and the membrane, thus reducing the strength of the lipid-protein interaction (Fig. 4, bottom panel) and accelerating the BR photocycle. Since the results of our studies correspond to a BR photocycle averaged over the whole ensemble of molecules in the solution (rather than the photocycle of a single BR molecule), a gradual increase of the cholesterol concentration leads to a gradual increase of the BR photocycle rate.

P.K.K., V.V.C. and V.I.B. are supported by the Ministry of Science and Higher Education of the Russian Federation (agreement \#075-00337-20-03, project FSMG-2020-0003).

1. L.A. Bulavin, D.V. Soloviov, Yu.E. Gorshkova et al. Structural transition in a lipid-water liquid system. Ukr. J. Phys. 57, No. 6, 623 (2012).

2. J. Eisenblätter, R. Winter. Pressure effects on the structure and phase behavior of dmpc-gramicidin lipid bilayers: A synchrotron SAXS and 2H-NMR spectroscopy study. Biophys. J. 90, 956 (2006).

3. C. Bernsdorff, A. Wolf, R. Winter et al. Effect of hydrostatic pressure on water penetration and rotational dynamics in phospholipid-cholesterol bilayers. Biophys. J. 72, 1265 (1997).

4. D.V. Soloviov, L.A. Bulavin, V.I. Gordeliy et al. Neutron scattering investigations of the lipid bilayer structure pressure dependence. Nucl. Phys. At. Energ. 13, No. 1, 83 (2012).

5. D.V. Soloviov, Y.E. Gorshkova, O.I. Ivankov et al. Ripple phase behavior in mixtures of DPPC/POPC lipids: SAXS and SANS studies. J. Phys. Conf. Ser. 351, 012010 (2012).

6. D. Soloviov, Y. Zabashta, L. Bulavin et al. Changes in the area per lipid molecule by P-V-T and SANS investigations. Macromol. Symp. 335, 58 (2014).

7. Y.E. Gorshkova, A.I. Kuklin,V.I. Gordeliy. Structure and phase transitions of DMPC multilamellar vesicles in the presence of $\mathrm{Ca}_{2}+$ ions. J. Surf. Investig. X-ray Synchrot. Neutr. Techn. 11, 27 (2017).

8. L.A. Bulavin, D.V. Soloviov, A.I. Kuklin et al. Small-angle $\mathrm{X}$-ray scattering and differential scanning calorimetry studies of DPPC multilamellar structures containing membranotropic agents of different chemical nature. Ukr. J. Phys. 60, 905 (2015).

9. L.A. Bulavin, D.V. Soloviov, V.I. Gordeliy et al. Lyotropic model membrane structures of hydrated (DPPC: DSC and small-angle X-ray scattering studies of phase transitions in the presence of membranotropic agents. Phase Trans. 88, $582(2015)$.

10. A.O. Krasnikova, N.A. Kasian, O.V. Vashchenko et al. Effect of oxyethilated glycerol cryoprotectants on DPPC model lipid membranes structure and phase. Probl. Cryobiol. Cryomed. 25, No. 2, 186 (2015).

11. O.V. Vashchenko, S.V. Shishkina, N.A. Kasian et al. Formation of antibiotic cycloserine complexes with stearic acid and its calcium and magnesium salts: From quantum mechanical modeling to studies of membranotropic action. Funct. Mater. 26, 673 (2019).

12. M. Zhernenkov, D. Bolmatov, D. Soloviov et al. Revealing the mechanism of passive transport in lipid bilayers 
via phonon-mediated nanometre-scale density fluctuations. Nature Commun. 7, 11575 (2016).

13. D. Soloviov, Y.Q. Cai, D. Bolmatov et al. Functional lipid pairs as building blocks of phase-separated membranes. Proc. Natl. Acad. Sci. U.S.A. 117, 4749 (2020).

14. M. Bogdanov, E. Mileykovskaya, W. Dowhan et al. Lipids in the assembly of membrane proteins and organization of protein supercomplexes: Implications for lipid-linked disorders. In: Lipids in Health and Disease. Edited by P.J. Quinn, Xiaoyuan Wang (Springer, 2008), SCBI, 49 pp. 197-239.

15. O.I. Ivankov, E.V. Ermakova, T.N. Murugova et al. Interactions in the Model Membranes Mimicking Preclinical Conformational Diseases (Elsevier, 2020) [ISBN: 24519634].

16. N. Ntarakas, I. Ermilova, A.P. Lyubartsev et al. Effect of lipid saturation on amyloid-beta peptide partitioning and aggregation in neuronal membranes: Molecular dynamics simulations. Eur. Biophys. J. 48, 813 (2019).

17. M. Javanainen, H. Martinez-Seara, I. Vattulainen. Nanoscale membrane domain formation driven by cholesterol. Sci. Rep. 7, 1143 (2017).

18. B.L. Stottrup, S.L. Keller. Phase behavior of lipid monolayers containing DPPC and cholesterol analogs. Biophys. J. 90, 3176 (2006).

19. J.H. Ipsen, G. Karlström, O. Mourtisen et al. Phase equilibria in the phosphatidylcholine-cholesterol system. Biochim. Biophys. Acta 905, 162 (1987).

20. O. Edholm, J.F. Nagle. Areas of molecules in membranes consisting of mixtures. Biophys. J. 89, 1827 (2005)

21. I. Chizhov, D.S. Chernavskii, M. Engelhard et al. Spectrally silent transitions in the bacteriorhodopsin photocycle. Biophys. J. 71, 2329 (1996).

22. D. Bratanov, K. Kovalev, J.-P. Machten et al. Unique structure and function of viral rhodopsins. Nature Commun. 10, 4939 (2019).
23. I. Chizhov, G. Schmies, R. Seidel et al. The photophobic receptor from Natronobacterium pharaonis: temperature and $\mathrm{pH}$ dependencies of the photocycle of sensory rhodopsin II. Biophys. J. 75, 999 (1998).

24. I.V. Chizhov. Flash photolysis. In Encyclopedia of Biophysics (Springer, 2013) [ISBN: 978-3-642-16712-6].

25. K.H. Müller, T. Plesser. Variance reduction by simultaneous multi-exponential analysis of data sets from different experiments. Eur. Biophys. J. 19, 241 (1991).

26. T. Hianik, V.I. Passechnik. Bilayer Lipid Membranes. Structure and Mechanical Properties (Springer Sci. and Business Media, 1995) [ISBN: 0792335511].

Received 31.03.20

Translated from Ukrainian by O.I. Voitenko

\section{Л.А.Булавін, А.Е. Михайлов,}

П.К. Кузмічов, В.В. Чупін, В.І. Борщевсъкий,

І.В. Чіжсов, Д.В. Соловйов

\section{ВПЛИВ КОНЦЕНТРАЦЇ̈}

ХОЛЕСТЕРИНУ НА ФОТОЦИКЛ

БАКТЕРІОРОДОПСИНУ

$\mathrm{P}$ е $з$ ю м е

В роботі за допомогою методу спектроскопї з розділенням в часі проведено дослідження фотоциклу мембранного білка бактеріородопсину в залежності від концентрації холестерину в мембрані дипальмітоїфосфатидилхоліну (ДПФХ). Показано, що температурні залежності констант швидкостей переходів бактеріородопсину між проміжними станами задовольняють рівняння Ейрінга. Доведено, що додавання холестерину в мембрану ДПФХ приводить до прискорення фотоциклу бактеріородопсину. 